\title{
INTERDISCIPLINARIDADE NO ENSINO: PROBLEMA METODOLÓGICO OU QUESTÃO HISTÓRICA? (ABORDAGEM ONTOLÓGICA)
}

\author{
José Luís Vieira de Almeida ${ }^{1}$
}

Na discussão acerca da interdisciplinaridade, que se desenvolve no Brasil, predomina a idéia de que ela é um processo de integração entre disciplinas. Essa integração deve ser progressiva e, por isso, pode, inclusive, propiciar a fusão das disciplinas envolvidas. Nessa perspectiva, as relações interdisciplinares dependem, fundamentalmente, de procedimentos metodológicos que se viabilizam por meio do esforço dos professores e pesquisadores imbuídos da postura interdisciplinar.

Esta comunicação mostra que a conduta interdisciplinar não depende de procedimentos metodológicos, nem tampouco do esforço dos professores e pesquisadores, pois ela decorre de questões de natureza histórica. Portanto, é dessa premissa que se deve partir para alcançar uma compreensão da interdisciplinaridade que permita superar a fragmentação do conhecimento.

Esta fragmentação decorre da divisão social do trabalho imposta pelo modo de produção capitalista. Por isso, a análise das relações interdisciplinares não pode prescindir do exame do processo histórico que divide o trabalho.

$$
\text { Introdução }
$$

No Brasil, a discussão acerca da interdisciplinaridade no ensino está afeta ao campo dos estudos sobre currículo. Neste país, quando se aborda esta questão, pensa-se, quase sempre na integração das disciplinas.

Por isso, esta comunicação inicia-se pelo exame do sentido da palavra integração e o seu vínculo com a idéia de rede. Porém, antes desse debate, aborda-se, de forma breve, a relação entre a idéia de interdisciplinaridade e transversalidade, que é uma peculiaridade brasileira.

A crítica da noção de que as relações interdisciplinares têm por base a integração das disciplinas, o que confere a ela um cunho metodológico, é desenvolvida a partir da história, tomando-se por referência a divisão social do trabalho.

Busca-se, assim, explicar a divisão do conhecimento a partir da divisão social do trabalho, o que inviabiliza a compreensão da interdisciplinaridade como resultado da integração das disciplinas.

\footnotetext{
${ }^{1}$ Universidade Estadual Paulista - UNESP - Campus de São José do Rio Preto Rua Antonio Castelar de Franceschi no 3471 CEP 13631-335 - Pirassununga - SP joseluisv@terra.com.br
} 
Interdisciplinaridade e Transversalidade

Embora a discussão dos Parâmetros Curriculares Nacionais (2000) não esteja entre os objetivos desta comunicação, cabe esclarecer que neles a relação interdisciplinar no âmbito do ensino é chamada de transversal, o que restringe a interdisciplinaridade à pesquisa. Assim, para os autores dos Parâmetros Curriculares Nacionais, os dois termos são sinônimos. Essa concepção funda-se num duplo equívoco, pois, primeiro, as relações interdisciplinares apresentam as mesmas características, tanto na pesquisa quanto no ensino e, segundo, interdisciplinar não é sinônimo de transversal. Em outras palavras, a relação interdisciplinar se dá entre as disciplinas nela envolvidas e, por isso, o seu desenvolvimento não depende de um elemento exterior a elas, o tema transversal. Dessa perspectiva, ele passa a ser o responsável pelo vínculo entre as disciplinas.

A integração das disciplinas e a organização da sociedade

O exame do termo integração mostra que, para as ciências humanas contemporâneas, ele é entendido como o estabelecimento de relações harmônicas entre elementos de um sistema, por exemplo, o professor e o aluno, ou o indivíduo e a sociedade. Esse sistema harmônico é restrito a uma instituição ou a um conjunto de instituições, quando se pretende analisar estruturas complexas como, por exemplo, a sociedade urbano-industrial. Na perspectiva de compreender as relações sociais como um sistema, cuja harmonia é alcançada e mantida pelo preceito da integração entre os seus elementos, surge a figura da "rede", baseada na lógica de funcionamento dos computadores.

A idéia de que as relações sociais se estabelecem do mesmo modo como se movimenta a informação nos computadores - em forma de rede - faz da integração a base da organização social. A figura da "rede", entendida como um grande número de elementos integrados harmoniosamente, quando aplicada à análise da sociedade, elimina os conflitos ou os restringe, de modo a que possam ser controlados por um operador, ou por um jogador, uma vez que os computadores também podem reproduzir jogos.

A compreensão das relações sociais como uma "rede", na qual os conflitos se desenvolvem de modo previsível e, por isso, podem ser controlados, suscita uma questão: quem controla este "imenso computador" chamado sociedade? A resposta para aqueles que reduzem a sociedade a um computador é simples: o Estado, um Estado neutro e asséptico, capaz de defender o interesse geral. A concepção de interesse geral é aplicável numa sociedade homogênea, sem classes, que só pode existir atualmente num programa para computadores. A sociedade real é heterogênea e conflituosa e, por isso, não pode ser reproduzida pela informática. Cabe observar que o Estado reproduz a heterogeneidade e os conflitos da sociedade, pois ele não está acima, mas sim dentro dela. Assim, a heterogeneidade e os conflitos próprios da sociedade não são defeitos, ou 
"buracos na rede", são suas características, resultantes de uma construção histórica. Quando se concebe o conflito como um defeito ou uma anomalia, nega-se a história.

A organização social dos dias de hoje expressa o resultado dos conflitos que permitiram a superação das formas de organização da sociedade que a antecederam; por exemplo, o capitalismo resulta da superação do feudalismo. Entendida como o palco dos conflitos humanos, tanto coletivos quanto individuais, a sociedade não pode ser perfeita e nem harmônica: a perfeição cede lugar ao conflito e a harmonia à superação da contradição expressa pelo conflito. Desse modo, não se trata de perpetuar o conflito, mas de superar a contradição nele manifestada; porém a superação de uma contradição permite a expressão de outra que deve também ser superada. Por isso, o processo de superação das contradições é histórico, tanto no plano pessoal, quanto no coletivo e no social. Quando a sociedade é compreendida como uma rede de relações harmônicas, as contradições desaparecem e, sem elas, inexiste o movimento de superação que se expressa na história.

A noção de rede enfoca as relações sociais apenas na perspectiva da quantidade: quanto maior o número de elementos envolvidos e quanto maior a comunicação entre eles, mais perfeita é a rede e, por analogia, mais democrática é a sociedade. Os conflitos e as contradições, ao contrário, conferem às relações sociais uma outra dimensão: a da qualidade. A dinâmica da sociedade, no dia a dia das pessoas, dos grupos e das classes sociais é constituída de dois movimentos, o da quantidade, que pode ser representado pela linearidade da rede, e o da qualidade, responsável pelas transformações efetivas. Ela não pode ser representada de modo linear, como uma rede, pois sua característica principal é a imprevisibilidade. Não se pode conhecer a priori a sua extensão e profundidade. As mudanças decorrentes dela não podem ser previstas antecipadamente; por exemplo, a conjuntura que se apresentava na Alemanha em maio de 1989 não indicava a queda do "Muro de Berlim" seis meses mais tarde.

A figura mais adequada à representação da qualidade é a espiral entendida não apenas no seu aspecto circular aberto, mas, sobretudo, na possibilidade de ascendência ou descendência, que confere ao movimento diferentes estados, bem como, elimina a idéia da linha reta ou da rede, que oferecem uma falsa noção de totalidade, uma vez que a visualização das suas extremidades pode ser conseguida a partir de qualquer um de seus pontos. Além disso, a figura da reta ou da rede privilegia a noção de ascendência, o sentido contrário é quase sempre entendido como retrocesso ou atraso. A idéia de que a reta possui um sentido correto, o ascendente, e outro incorreto, o descendente, é extraída principalmente do cotidiano, como por exemplo, a contramão, que estabelece o sentido do tráfego, ou a partida e a chegada, o atrás e a frente.

A evolução, como sinônimo de ascendência, é amplamente difundida na sociedade urbano-industrial: ela é apresentada como uma "tendência natural", não no sentido de inerente à natureza humana, mas de inevitável. Desse modo, a cada dia que passa, as relações sociais evoluem como os fatos históricos numa "linha do tempo". Este 
"darwinismo social" aparece também quando se pensa na rede, na qual o processo evolutivo se dá com a sua expansão, ou com o aumento do número de ligações entre os seus nódulos. Não há preocupação quanto à qualidade da expansão representada pelos canais de comunicação estabelecidos entre os nódulos. Na sociedade, não há relação direta entre a quantidade e a qualidade, pois a primeira não implica a segunda. Nos Estados modernos, o crescimento, tanto da extensão das redes interinstitucionais quanto do número de canais de comunicação entre elas, não tem implicado, diretamente, a qualidade do processo de democratização das instituições.

\section{O currículo e a interdisciplinaridade}

A construção curricular, bem como a sua implantação, avaliação e reformulação expressam relações sociais que, como tal, são conflituosas, heterogêneas e complexas. Nas últimas três décadas, de modo particular entre os educadores brasileiros, o currículo tem sido abordado como um processo técnico de encadeamento de disciplinas. Esta concepção vem sofrendo críticas e, em decorrência delas, tem sido, ao mesmo tempo, aperfeiçoada por estudiosos, dispostos a revigorar concepções historicamente superadas.

A crítica conservadora da idéia de que o currículo é um elenco de disciplinas tem por base a idéia de rede. Do mesmo modo que as relações sociais, o conjunto de disciplinas é uma rede na qual cada nódulo indica a relação entre disciplinas e as ligações entre os nódulos atestam a existência de uma atitude interdisciplinar.

A figura da rede é, no mínimo, insuficiente para representar a atitude interdisciplinar, na medida em que não discute a sua qualidade e nem explicita o modo pelo qual ela pode ser disseminada entre os docentes e acadêmicos. A idéia de que a interdisciplinaridade consiste na comunicação entre as disciplinas dispostas em forma de rede não supera a noção de encadeamento de disciplinas, apenas muda a sua disposição, reafirmando a linearidade que permanece dissimulada. A idéia de que o currículo é um modo de encadear disciplinas, seja por meio da configuração simplesmente linear ou dissimulada na forma da rede, reduz a interdisciplinaridade a uma questão quantitativa, daí a necessidade de classificá-la e distingui-la a partir do grau de integração. Assim, a relação entre as disciplinas recebe um nome específico de acordo com a quantidade da integração existente entre elas, como por exemplo, multi, pluri, inter ou transdisciplinaridade. Nesta classificação, a multidisciplinaridade se caracteriza por uma superposição de disciplinas que não estabelecem relação aparente entre si; a pluridisciplinaridade consiste na superposição de disciplinas cujo objeto de estudo é correlato, em outras palavras, sugere a possibilidade da ocorrência de relação entre elas; a interdisciplinaridade indica a existência de intercâmbio por parte de duas ou mais disciplinas, sem levar em conta o modo como ele ocorre, a constatação e a classificação são suficientes. Por fim, a transdiciplinaridade exprime a interdisciplinaridade no seu maior grau, na medida em que dela resultam uma ou várias novas disciplinas decorrentes da relação entre disciplinas já existentes. Há diferentes critérios por meio dos quais se podem classificar as relações entre disciplinas, o que implica diversificação 
da nomenclatura. As diferenças, tanto do ponto de vista dos critérios quanto das denominações, são aparentes, pois o princípio que os orienta é o mesmo: a quantidade.

Divisão do trabalho e divisão do conhecimento

A superação do modo de compreender as relações interdisciplinares a partir das classificações e suas respectivas nomenclaturas, pautadas na noção de quantidade, requer uma abordagem histórica do processo de divisão social do trabalho, tanto no plano das atividades manuais quanto intelectuais.

A fragmentação no campo das ciências é, de modo geral, justificada pelo acúmulo de conhecimentos por parte delas no transcorrer da história da humanidade, principalmente a partir dos séculos XVII e XVIII, com o desenvolvimento das ciências naturais, e, no século seguinte, por meio do crescimento quantitativo dos conhecimentos sistematizados no âmbito das ciências humanas. Entendida dessa maneira, a divisão das ciências é uma solução que permite a acomodação dos conhecimentos produzidos em compartimentos: é como se o aumento da quantidade de conhecimentos provocasse a ruptura dos rígidos limites da ciência. Eles são rígidos porque o conhecimento é análogo ao dinheiro acumulado pelo capitalista e a ciência é o cofre onde ele é guardado. Como não há cofres flexíveis, a solução é fabricar mais cofres, quanto maior for a quantidade de conhecimento acumulado. Este modo de pensar, que assemelha o conhecimento ao dinheiro, atribui a ambos as mesmas propriedades: eles devem ser acumulados e sua apropriação deve ser individual e, na medida do possível, secreta, o que, no caso do conhecimento, explica a dificuldade de acesso da quase totalidade da população aos restritos círculos acadêmicos.

Os limites rígidos das ciências não são atributos delas, decorrem de uma imposição da ideologia que justifica a fragmentação do trabalho humano, seja ele manual ou intelectual, em nome de uma suposta racionalidade, responsável pela eficiência e pela eficácia do processo produtivo. A mesma disciplina que submete o trabalhador manual aos interesses do capital subordina também o trabalhador intelectual, o pesquisador, a estes interesses, por meio da formalização dos limites das ciências, cristalizando a idéia de um mundo sem conflitos, homogêneo e harmônico.

A discussão acerca da interdisciplinaridade que se desenvolve no Brasil, nas últimas três décadas, parte da constatação dos limites de cada ciência e se esforça em apontar a existência de possibilidades de eles serem quebrados, para o bem das próprias ciências. A proposta de supressão dos limites formais de cada ciência não os supera, ao contrário, recupera-os e, ao mesmo tempo, logra dissimulá-los, na medida em que a denúncia do formalismo, que impede ou dificulta a integração entre as ciências, e as possibilidades de que tais barreiras sejam transpostas são apresentadas por meio de outra formalização: a divisão por graus de intensidade e a conseqüente delimitação do relacionamento interdisciplinar tendo a quantidade por critério. A gradação e a idéia de 
acumulação são inerentes a quaisquer critérios quantitativos, daí a necessidade da distinção dos graus de integração entre as disciplinas. Como decorrência do estabelecimento de graus, o processo interdisciplinar segue uma trajetória que parte do menor, a pluridisciplinaridade, em direção ao maior, a transdisciplinaridade: a integração completa é o destino de todo o conhecimento produzido pela humanidade. Nessa perspectiva, os obstáculos que hoje dificultam ou impedem a realização da interdisciplinaridade devem ser transpostos ao longo do tempo, visto que ela é inerente à natureza do conhecimento humano. A dissociação das disciplinas é entendida como uma necessidade decorrente do acúmulo de conhecimentos, por isso a sua integração é uma questão de maturidade a ser atingida numa progressão linear, do mesmo modo que uma pequena planta, com o tempo, se torna uma grande árvore.

Quando a integração das disciplinas é compreendida como natural, semelhante ao crescimento de uma árvore, os obstáculos a esta vocação do conhecimento humano são atribuídos aos professores e pesquisadores: eles são responsabilizados pela interposição de barreiras à interdisciplinaridade. Trata-se, portanto, de um problema individual. Desse modo, a integração das disciplinas passa a depender da vontade individual de cada pesquisador. Estes problemas poderiam ser resolvidos se os pesquisadores fossem submetidos às modernas práticas de treinamento de executivos. Elas são baseadas na superação do individualismo pelo trabalho em equipe, afinal a realização da atividade depende da simples soma dos esforços individuais voltados para a transposição de um obstáculo, como por exemplo, a travessia de um rio ou o escalar um pico.

A divisão das ciências não decorre de um momento particular da história da humanidade quando a farta produção de conhecimento implicava dificuldades na sua organização. Esse argumento reduz o problema da fragmentação das ciências, bem como a sua integração, a uma mera questão funcional, cuja solução é análoga à acumulação do dinheiro a ser guardado em cofres. A alegada funcionalidade da delimitação estrita e estreita do campo de conhecimento a ser investigado por cada ciência serve de anteparo para esconder os reais objetivos e conseqüências desse processo. Ao fragmentar o trabalho manual, o modo de produção capitalista estabeleceu, por meio dos processos de organização do trabalho, como o taylorismo e o fordismo, não só o que deve ser produzido, mas também como produzir, controlando, nos seus mínimos detalhes, o comportamento do trabalhador. A divisão do conhecimento humano em ciências particulares e particularizadas visa ditar o modo pelo qual este conhecimento deve ser produzido e controlar o comportamento do pesquisador neste processo.

Cada ramo resultante da divisão das ciências empenha-se na adoção de metodologias próprias para a coleta, organização e análise dos dados. A diferenciação metodológica, mesmo quando pouco significativa, é, via de regra, o atestado da especificidade da ciência particular. Dessa forma, a especificidade da ciência passa a ser determinada pelo caráter particular da metodologia por ela adotada, que, na maioria dos casos, recebe a denominação de método, como por exemplo, métodos matemáticos ou métodos para o ensino de línguas. Esta postura desloca a especificidade da ciência do 
enfoque que ela atribui ao seu objeto de estudo para a particularidade metodológica, o que, em muitos casos, pode reduzir a produção de conhecimento a uma atividade manual, dissimulada por uma atitude tida como científica, visto que o objeto de investigação é preterido em favor de um suposto rigor metodológico.

A situação analisada, do ponto de vista da ciência, se reproduz na discussão da interdisciplinaridade. Quando a integração de disciplinas é enfocada a partir da identificação das semelhanças e das diferenças metodológicas entre, no mínimo, dois ramos do conhecimento, a distinção aparece apenas como uma questão formal e, como tal, o seu desenvolvimento consiste no estabelecimento de uma nova formalização, com base na soma dos termos, visto que a separação das ciências está pautada na subtração. O processo de separação de uma ciência em vários ramos do conhecimento não se deu ao mesmo tempo e, por isso, não pode ser entendido como uma divisão. A figura mais adequada para representá-lo é a subtração. A interdisciplinaridade entendida apenas como uma formalização diferente daquela que se obteve com a separação das ciências em vários ramos, desconhece ou ignora deliberadamente a análise histórica, fundamental para o entendimento do problema. A ignorância ou o descaso com respeito ao processo histórico que propiciou e justificou a segmentação das disciplinas, faz da dificuldade ou impossibilidade de relação entre elas, uma questão pessoal do pesquisador ou grupo de pesquisadores.

Os argumentos que explicavam e justificavam a separação das disciplinas nos séculos XVIII e XIX, quando compreendidos numa perspectiva da negação do movimento da história, continuam válidos ainda hoje: o conhecimento humano continua a ser acumulado de modo intenso e o seu aprofundamento continua a exigir uma especificação cada vez maior das disciplinas.

A divisão social do trabalho é o modo pelo qual se estabelecem as relações de dominação no capitalismo, que se manifestam, no âmbito do conhecimento, por meio da fragmentação das ciências. Ela consiste numa demarcação de "territórios", cujos domínios são protegidos da invasão de "estrangeiros". A consolidação dos domínios de cada ciência particular, a demarcação dos seus "territórios", se dá pela criação de um vocabulário, de procedimentos metodológicos e, em alguns casos, de rituais, em nome da especificidade do objeto de estudo da ciência. $\mathrm{O}$ acesso a este aparato, denominado científico só é permitido aos iniciados naquele campo do conhecimento humano, os outros são leigos, como numa seita ou congregação religiosa. O trabalho, seja do ponto de vista da produção de bens e serviços ou de conhecimentos, é coletivo, mas nos dois casos a apropriação do seu resultado é individual, seja pelo capital, no primeiro caso, ou pelos confrades de cada ciência particular, quando se trata do conhecimento. Assim como a acumulação de capital implica exercício da dominação sobre o trabalho, a fragmentação das ciências garante a submissão do leigo ao cientista, mesmo quando este leigo é também homem de ciência. 
A fragmentação do conhecimento humano não atende apenas aos interesses daqueles que perpetuam a sua divisão, ela também se vincula a disputas externas, ao que tem sido chamado incorretamente de "comunidade científica". Ela subsidiou, por exemplo, a "guerra fria", sobretudo na confecção das armas nucleares, alimenta a concorrência entre laboratórios farmacêuticos, no campo da produção de novos medicamentos, e a competição entre as indústrias de modo geral. Os exemplos citados indicam a quem serve a ciência dividida.

O inevitável predomínio das leis de mercado no mundo científico decorre do fato de que o conhecimento é produzido e transmitido sob a influência das relações sociais. Em outras palavras, as ciências reproduzem as relações de poder vigentes na sociedade em que estão inseridas, inclusive e, talvez principalmente, as ciências naturais, por evocarem com maior ênfase o preceito da neutralidade científica.

No debate, que se trava no campo das ciências, acerca da reprodução das relações de poder vigentes na sociedade, predominam duas posições: a que advoga a neutralidade científica e aquela que, ao negá-la, reduz a produção de conhecimentos a uma extensão das relações de dominação próprias da sociedade na qual ela se insere - $\mathrm{o}$ modo de produção capitalista. As duas posições, apesar de antagônicas, ignoram o fato de que não se está discutindo uma ciência genérica e, portanto, indeterminada do ponto de vista social e histórico, trata-se da ciência fragmentada. Esta fragmentação é produzida pelas relações que se estabeleceram entre as ciências e o modo de produção capitalista. Elas foram necessárias para que ambos pudessem se consolidar, superando, ao mesmo tempo, o modo de produção feudal e a resistência do modo de pensar a ele vinculado, ao estreitamento das relações entre o ser humano e a natureza, orientação central na constituição do pensamento científico, particularmente entre os séculos XVIII e XIX. Não se trata, portanto, de discutir a neutralidade da ciência ou a sua subordinação ao modo de produção capitalista, trata-se de elucidar a maneira pela qual tais relações se estabeleceram e de que modo elas podem ser superadas. Nos dias de hoje, não há dúvida que tanto o capitalismo quanto as ciências estão consolidados, não havendo, portanto, razões históricas para que tais relações perdurem.

\section{As relações entre as disciplinas}

O cientista ou o filósofo, por maior que seja a sua genialidade individual, não pode transpor o tempo histórico em que vive, conforme afirma GOLDMANN (1970), no âmbito da ciência, e LEFEBVRE (1967), no da filosofia, mas, ao mesmo tempo, deve esforçar-se por interpretá-lo, seja no âmbito das ciências naturais ou sociais. Os séculos XIX e XX são marcados pela consolidação do capitalismo. Esta compreensão permite discutir as relações entre a produção de conhecimentos e a organização da sociedade em bases diferentes das formuladas quando, tanto o capitalismo quanto as ciências não estavam consolidados. Não se trata de eliminar os vínculos entre as ciências e a sociedade, o que implicaria a re-elaboração do preceito da neutralidade científica; trata-se, ao contrário, de reconhecê-los para interpretá-los e, com base nesta 
interpretação, estabelecer os seus contornos. A rediscussão das relações entre as ciências e a sociedade não pode ser desenvolvida por indivíduos isolados, pois ela é coletiva e histórica. A questão da interdisciplinaridade é fundamental neste processo, na medida em que oferece alternativas à fragmentação das ciências, cuja relevância está vinculada à superação dos parâmetros fundados na quantidade, por critérios com base na qualidade.

Os objetos das ciências têm sido, tradicionalmente, o marco inicial das discussões sobre a relação interdisciplinar. As semelhanças entre eles são, via de regra, o referencial a indicar as possibilidades de relacionamento entre as disciplinas. Estabelecidas as semelhanças, parte-se então para a identificação das diferenças, sempre na perspectiva de minimizá-las ou, até mesmo, eliminá-las. As dificuldades ou a impossibilidade de realização desta tarefa justificam a defesa da necessidade de fusão dos objetos, dando origem a um outro que os unifica. Colocada deste modo, a questão dos objetos das ciências, na relação interdisciplinar, permanece na esfera da quantidade, fundada nos critérios de semelhança ou diferença entre as disciplinas. Estes critérios enrijecem os objetos das ciências e, sob esta rigidez se estabelece a interdisciplinaridade. Mesmo admitindo-se a possibilidade de fusão entre eles, o resultado será sempre um outro objeto igualmente rígido, atendendo aos propósitos de re-ordenamento da fragmentação. É preciso abandonar a concepção de que cada ciência tem o seu objeto particular, sem o qual ela não é científica. Os objetos não são próprios das ciências, eles estão na natureza, na sociedade, ou em ambas e, cada ciência, vai se apropriar deles e examiná-los sob um determinado enfoque. Cada ciência desenvolve o seu enfoque, que é necessariamente diferente das demais. Assim, deve-se discutir a relação entre as ciências a partir do enfoque ou enfoques que cada uma delas atribui a um objeto.

A interdisciplinaridade qualitativa só pode ocorrer a partir da relativização do objeto e da ênfase nas diferenças de enfoque de cada ciência. Nesta perspectiva, a fusão dos enfoques de duas ou mais ciências não implica seu desaparecimento para dar lugar ao que resultou desse processo, ao contrário, todos os enfoques convivem de modo conflituoso, visto que não se trata de uma relação "edipiana". Cada fusão pode apresentar mais de um resultado, desde que tais resultados respondam a necessidades históricas. Apesar da ênfase com que foi tratada aqui, a fusão de enfoques de duas ou mais ciências não é um imperativo no processo interdisciplinar, ela só ocorre quando reclamada pelas condições históricas.

Conclusão: a interdisciplinaridade no ensino

Há uma crença generalizada de que, no ensino, as relações interdisciplinares são facilitadas quando o professor reconhece os limites da sua disciplina e os expressa quando ensina. Assim, um conceito, uma definição, ou um teorema não se explicam por si mesmos, a sua explicitação depende de outros conceitos ou definições já ensinados. Porém, quando se concebe o conhecimento como um processo cumulativo, o conceito 
que se está ensinando é hierarquicamente superior aos abordados anteriormente. Desta forma, a disciplina ministrada por cada docente se torna, para ele, a mais completa e abrangente e, assim, a relação interdisciplinar se limita a um procedimento metodológico ou a uma estratégia de ensino.

No campo do ensino, as dificuldades de relacionamento entre as disciplinas podem se agravar, quando comparadas à sua expressão no âmbito da produção de conhecimentos, tendo em vista que a fragmentação das ciências passa a ser um valioso instrumento para o exercício do poder no âmbito doméstico da unidade educacional, que pode se traduzir, por exemplo, na disputa por cargos administrativos, ou por uma maior carga horária na grade curricular de um curso. As posturas comuns no exercício do poder na área do ensino não se distinguem daquelas que predominam na sociedade. Nas relações de poder da sociedade brasileira, predominam as condutas autoritárias, e elas são difundidas, nas instituições de ensino, ainda que de forma dissimulada. Uma das maneiras de dissimulá-las é a redução da interdisciplinaridade a um mero formalismo discursivo. $O$ exercício da interdisciplinaridade no ensino não convive com o autoritarismo, pois exige mudanças radicais que vão desde a concepção de ensino, passando pela postura assumida pelos docentes nos processos de construção ou reformulação curricular e na relação professor aluno, principalmente no que se refere ao acesso ao conhecimento, que não é propriedade individual do docente, mas uma produção coletiva e histórica de toda a humanidade.

O desenvolvimento de uma atitude interdisciplinar no ensino não depende da vontade individual de cada docente. Ela resulta de um esforço coletivo, fruto da consciência de que, no conhecimento não há hierarquia, deve-se ao contrário, estabelecer prioridades a partir de critérios, já explicitados no currículo como, por exemplo, o perfil do aluno que se deseja formar. A interdisciplinaridade não pode ser entendida como obrigatória, ou como uma necessidade de se "estar na moda". Ela é um processo a ser desencadeado quando o corpo docente estiver disposto a assumir uma postura interdisciplinar. Esta relação interdisciplinar não deve estabelecer como critério a especificidade das disciplinas, assumindo assim uma perspectiva unilateral, os seus referenciais são o currículo e o projeto pedagógico nele explicitado.

A postura interdisciplinar no ensino não pode prescindir do conflito entre posições opostas. A principal regra deste debate é o respeito à divergência e o seu objetivo é a superação das dificuldades ou contradições que se verificam na prática docente. A disposição em assumir uma postura interdisciplinar, que é coletiva e histórica, no dia a dia da atividade docente implica aceitar a divergência e o conflito. Neste debate ninguém ganha ou perde como ocorre, por exemplo, nos confrontos partidários em vésperas de eleições, todos são participantes. Esta pode ser a única condição de igualdade entre os debatedores. O único resultado que, de antemão, pode-se esperar dele é a constatação de que o êxito do ensino está na diferença e não na semelhança, na dúvida e não na certeza. 
Referências Bibliográficas

Goldmann, L. (1970). Ciências Humanas e Filosofia: o que é a sociologia? São Paulo: DIFEL.

Lefebvre, H. (1967) Metafilosofia. Rio de Janeiro: Civilização Brasileira.

Secretaria, E. F. (2000) Parâmetros Curriculares Nacionais: apresentação dos temas transversais. Rio de Janeiro: DP\&A. 